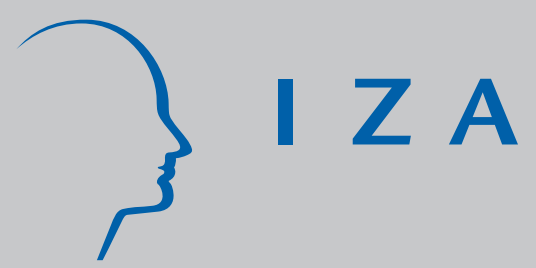

IZA DP No. 653

Money for Health: The Compensating Variation of Cardiovascular Diseases

Wim Groot

Henriette Maassen van den Brink

Erik Plug

November 2002 


\title{
Money for Health: The Compensating Variation of Cardiovascular Diseases
}

\author{
Wim Groot \\ University of Amsterdam and Maastricht University \\ Henriette Maassen van den Brink \\ University of Amsterdam \\ Erik Plug \\ University of Amsterdam, Tinbergen Institute and IZA Bonn
}

\author{
Discussion Paper No. 653 \\ November 2002
}

\author{
IZA \\ P.O. Box 7240 \\ D-53072 Bonn \\ Germany \\ Tel.: $+49-228-3894-0$ \\ Fax: +49-228-3894-210 \\ Email: iza@iza.org
}

This Discussion Paper is issued within the framework of IZA's research area Evaluation of Labor Market Policies and Projects. Any opinions expressed here are those of the author(s) and not those of the institute. Research disseminated by IZA may include views on policy, but the institute itself takes no institutional policy positions.

The Institute for the Study of Labor (IZA) in Bonn is a local and virtual international research center and a place of communication between science, politics and business. IZA is an independent, nonprofit limited liability company (Gesellschaft mit beschränkter Haftung) supported by the Deutsche Post AG. The center is associated with the University of Bonn and offers a stimulating research environment through its research networks, research support, and visitors and doctoral programs. IZA engages in (i) original and internationally competitive research in all fields of labor economics, (ii) development of policy concepts, and (iii) dissemination of research results and concepts to the interested public. The current research program deals with (1) mobility and flexibility of labor, (2) internationalization of labor markets, (3) welfare state and labor market, (4) labor markets in transition countries, (5) the future of labor, (6) evaluation of labor market policies and projects and (7) general labor economics.

IZA Discussion Papers often represent preliminary work and are circulated to encourage discussion. Citation of such a paper should account for its provisional character. A revised version may be available on the IZA website (www.iza.org) or directly from the author. 
IZA Discussion Paper No. 653

November 2002

\section{ABSTRACT \\ Money for Health: The Compensating Variation of Cardiovascular Diseases*}

This paper introduces a new method to calculate the extent to which individuals are willing to trade money for improvements in their health status. An individual welfare function of income (WFI) is applied to calculate the compensating income variation of health impairments. We believe that this approach avoids various drawbacks of alternative willingness-to-pay methods. The WFI is used to calculate the compensating variation of cardiovascular diseases. It is found that for a 25-year old male the compensating variation of a heart disease ranges from 160,000 Euro to 430,000 Euro depending on the welfare level. This is about 8,000 to 32,000 Euro for an additional life year, depending on the quality of life. The compensating variation declines with age and is lower for women than for men. The estimates further vary by the discount rate chosen. The estimates of the compensating variation are generally higher than the money spent on heart related medical interventions per QALY.

JEL Classification: $\quad I 10, \mid 12$

Keywords: compensating income variations, cardiovascular disease, subjective income evaluation

Corresponding author:

Erik Plug

Department of Economics and Econometrics

University of Amsterdam

Roetersstraat 11

1018 WB Amsterdam

The Netherlands

Tel.: +31205254311

Fax: +3120 5254310

Email: plug@fee.uva.nl

\footnotetext{
*We thank two anonymous referees for their valuable comments.
} 


\section{Introduction}

Economic evaluations have become an important tool to allocate (public) money for health care. Most evaluations are based on an assessment of the costeffectiveness or cost-utility of health care interventions. The most well-known instruments applied that shed light on the benefits of health care interventions are the quality adjusted life years or QALY's. A QALY measures the amount of healthy years gained by a medical intervention. If QALY's are combined with the costs of such an intervention, it can be calculated how much money has to be spent on a medical intervention per QALY. This can be used to rank medical interventions by their effectiveness (i.e. the lowest costs necessary to gain one QALY). This information can be useful to achieve a more efficient allocation of (public) health care expenditures. However, a true economic evaluation of health interventions not only requires knowledge about the costeffectiveness but also on the value individuals attach to the health improvement. Cost-effectiveness and cost-utility studies only provide information whether one intervention is more cost effective than another, not whether it contributes to improving welfare. In the words of Mishan (1988): "To be rather rude about it, the analysis of cost-effectiveness can be described as a truncated form of cost benefit analysis...." (p110; see also Kenkel, 1997). The benefits of a program can be determined by calculating the willingness to pay by individuals for the health improvement obtained by the intervention. The willingness to pay reflects the extend to which individuals are willing to trade money for improvements in their health status. Only if the cost of the health improvement are less than the amount individuals are willing to sacrifice for this gain in their quality of life, the intervention constitutes a true welfare improvement. Labelle and Hurley (1992) argue that the difficulties of quantifying health related benefits within a willingness-to-pay methodology explain why cost-effectiveness analysis has received so much more attention and is more approved of in medical sciences than cost-benefit analysis. Indeed, a major reason for the lack of attention to the willingness to pay for health gains is that the methods for calculating the willingness to pay have several limitations and restrictions. The existing methods to calculate the willingness-to-pay can be classified by the way in which preferences are measured. Either preferences are deduced from observed behavior (revealed preference), or individuals are asked directly to state their preferences. The revealed preference method is mostly based on the hedonic wage or compensating wage differentials approach. The basic assumption of this approach is that health risks comprise an aspect of life that one would like to minimize or eliminate. Elimination of health risks and job hazards are costly, and resources spent on reducing health risks and job hazards can not be spent on other valuable goods. How much will be spent on health measures depends on the value individuals attach to a reduction in health risks. A survey of the hedonic wage approach and of the empirical studies that measure the monetary value of fatal and non-fatal health risks can be found in Viscusi $(1993,1997)$. The hedonic wage approach is not without problems. The most serious ones concern the problem of self-selection and generalization. Individuals who decide for a cer- 
tain type of behavior or workers who have chosen a specific occupation are not a random sample of the entire population, but rather a selected group for whom the (job or safety) hazards weigh less heavy than for individuals who made a different choice. Although there are several methods to account and correct for self-selection bias, none of them are completely satisfactory and some of them lead to outcomes that are decidedly disputable. Further, inferences about preferences are frequently based on the behavior of a specific group - for example occupational choices by workers, seat belt use by car drivers or expenditures on safety-capped bottles of aspirins by parents with young children - and are then generalized to the population as a whole.

The alternative approach to calculating the willingness-to-pay is to ask individuals directly how much they are willing to pay for the reduction or elimination of a (fatal) health risk. An approach in this field that has gained some considerable attention is the contingent valuation method. Respondents are asked to consider hypothetical contingencies and to place a specific monetary value on a change from one health status to another, or asked what the maximum amount is that he/she is willing to pay for the elimination of a health risk. A survey of the contingent valuation method to calculate willingness to pay is found in Diener, O'Brien and Gafni (1998).

This direct approach has some severe limitations as well. Respondents are usually confronted with hypothetical situations of which they have no personal experience. Nor might they ever have considered such situation before. Respondents may also find it difficult to fully understand and comprehend the actual risk involved in the situation. It is further frequently found that the subjective evaluations of risks differ from the objective risk (Viscusi, 1997). Finally, responses do not have any consequences for the individual involved. Individuals do not have to change their behavior, nor do they have to sacrifice anything as a result of the opinions they state. This may have the effect that individuals are less committed to their answers and makes the reliability of the responses questionable.

In this paper a new approach is taken to calculate the extend to which individuals are willing to trade money for improvements in their health status. By using a specific utility function, known as the Leyden Welfare Function of Income, we are able to estimate the compensating income variation needed to make someone with an health impairment as well of as someone without this specific health condition. This approach has the advantage that it is easy to apply and to understand. It uses information on the entire population, thereby avoiding the problems of self-selection and generalization associated with the hedonic wage approach. It further has the advantage that it does not require that respondents evaluate hypothetical situation, nor does it demand that individuals make assessments about the trade-off between risk evaluations and monetary returns.

The Leyden Welfare Function is developed and corroborated in a large body of research and has been used to calculate the compensating variation of changes 
in household size, climate, and schooling and intelligence. ${ }^{1}$ However, to the best of our knowledge, it has never been used to estimate the compensating variation of a health change. In particular we apply the method to calculate the compensating variation of a serious heart-attack or heart-problem. We use information on differences in mortality rates between individuals with and without a serious heart problem to determine the willingness to pay for a medical intervention. The reason to focus on heart diseases is twofold. First, coronary heart diseases are the most important mortality risk. In 1994 the mortality rate because of coronary heart diseases in the Netherlands was 150 per 100,000 for men and 110 per 100,000 for women. In 1994 the prevalence of coronary heart diseases is 11.9 per 1000 among men and 8.2 per 1000 for women. Secondly, the costs of medical interventions for heart diseases are often high, which make it relevant to ask how these costs compare to the value of the health benefits that are obtained by it.

The outline of this paper is as follows. In Section 2 we present a brief introduction to the Leyden welfare function of income. The data used for the empirical analysis are described in Section 3. The empirical results are found in Section 4. In Section 5 these findings will be the backbone for our measures of importance: the compensating variation of a cardiovascular disease. Section 6 concludes.

\section{The model}

In this paper we will monetarise health impairments using the idea of compensating income variation. To do so we require a utility function that describes the relationship between an individual's utility, income and health at time $t$. Suppose that we can write this utility function as

$$
U=U_{t}\left(y_{t}, h_{t}\right)
$$

where $y$ is income and $h$ is health, and where utility is increasing in both arguments $y$ and $h$. With this function the compensating income variation of a health change is calculated by solving equation

$$
U_{t}\left(y_{0 t}, h_{0 t}\right)=U_{t}\left(y_{1 t}, h_{1 t}\right)=u_{0}
$$

It follows that $y_{1 t}-y_{0 t}$ is the amount of money we should give to an individual whose health deteriorates and falls from $h_{0}$ to $h_{1}$ to make him or her just as well off as he or she was before the health change. We take the healthy individual as our point of reference represented by utility level $u_{0} \cdot{ }^{2}$ For any positive

\footnotetext{
${ }^{1}$ Examples are Van Praag and Kapteyn, 1973, Van Praag, Goedhart and Kapteyn, 1980, Hagenaars and Van Praag, 1985, Van de Stadt, Kapteyn and Van de Geer, 1985, Van Praag, 1991, Plug and Van Praag, 1998 and Plug, Van Praag and Hartog, 1999.

${ }^{2}$ Another way of measuring the monetary impact of a health change is to ask how much money we should take away in order to leave him or her as well off as he or she would be after the health change. This is known as the equivalent income variation. Equality between compensating and equivalent income variation exists if calculated amounts do not depend on the utility base we take as our reference. This happens if we assume homothetic preferences.
} 
monotonic transformation of the utility function, equality in (2.2) remains unaffected. Hence, the calculation of the compensating income variation at time $t$ $\left(\mathrm{CIV}_{t}=y_{1 t}-y_{0 t}\right)$ is a rather straightforward exercise, and can be done without posing any cardinal structure on our annual utility function.

A deteriorating health might also lead to utility losses because of a falling life expectancy. If we want to quantify the magnitude of this effect, we have to refine our compensating income variation measure.

We start with an individual who gets sick so that his or her health deteriorates and drops from $h_{0}$ to $h_{1}$. We further assume that this patient receives treatment and recovers completely after $k$ periods, but life expectancy is lowered and he or she has $m$ remaining years to live. Lifetime utility equals the sum of annual utilities ${ }^{3}$ which can be described as

$$
\begin{aligned}
& U\left(y_{11}, \ldots, y_{1 k}, y_{0 k+1}, \ldots, y_{0 m}, h_{11}, \ldots, h_{1 k}, h_{0 k+1}, \ldots, h_{0 m}\right)= \\
& \quad U_{1}\left(y_{11}, h_{11}\right)+U_{2}\left(y_{12}, h_{12}\right)+\ldots+U_{k}\left(y_{1 k}, h_{1 k}\right) \\
& \quad+U_{k+1}\left(y_{0 k+1}, h_{0 k+1}\right)+\ldots+U_{m}\left(y_{0 m}, h_{0 m}\right) .
\end{aligned}
$$

For an individual with perfect health, with perfect foresight, and with $n$ additional years to live, the sum over all the annual utilities equals

$$
\begin{aligned}
& U\left(y_{01}, \ldots, y_{0 m+n}, h_{01}, \ldots, h_{0 m+n}\right)= \\
& \quad U_{1}\left(y_{01}, h_{01}\right)+U_{2}\left(y_{02}, h_{02}\right)+\ldots+U_{m+n}\left(y_{0 m+n}, h_{0 m+n}\right) .
\end{aligned}
$$

If we compare the two states, the compensating income variation amount is found by solving equation

$$
\begin{aligned}
& U\left(y_{11}, \ldots, y_{1 k}, y_{0 k+1}, \ldots, y_{0 m}, h_{11}, \ldots, h_{1 k}, h_{0 k+1}, \ldots, h_{0 m}\right)= \\
& \quad U\left(y_{01}, \ldots, y_{0 m+n}, h_{01}, \ldots, h_{0 m+n}\right) .
\end{aligned}
$$

We obtain equality in lifetime utility in two steps. First we set all corresponding annual utilities equal, like we did in (2.2), to find the suitable annual monetary compensations in the first $k$ periods

$$
U_{1}\left(y_{1 t}, h_{1 t}\right)=U_{1}\left(y_{0 t}, h_{0 t}\right) \longrightarrow \operatorname{CIV}_{t}=y_{1 t}-y_{0 t} \text { for } t=1, \ldots, k .
$$

We then have to solve the problem that the number of annual utility terms is larger for individuals in perfect health. If we return to the sum of annual utilities for unhealthy individuals, we have implicitly assigned annual utility values equal to 0 to the status of death. Compared to the healthy individual, it is as if the unhealthy individual lost his of her annual utilities for the additional $n$ years

$$
U_{m+1}\left(y_{0 m+1}, h_{0 m+1}\right)+\ldots+U_{m+n}\left(y_{0 m+n}, h_{0 m+n}\right) .
$$

\footnotetext{
${ }^{3}$ To keep the model simple and traceable, the life utility function we present in this paper is additive and separable in annual utilities. We are aware that we do not need this function to be separable or even additive.
} 
We obtain the monetary equivalent of this particular sum of utilities if we use a specific positive monotonic transformation $\Psi$ that transforms each consecutive annual utility value into its monetary equivalent

$$
y_{0 t}=\Psi\left(U_{t}\left(y_{0 t}, h_{0 t}\right)\right)=V\left(y_{0 t}, h_{0 t}\right) \text { for all } t .
$$

If we redefine lifetime utilities in (2.3) and (2.4) and replace all annual utility functions $U$ with $V$, the final Compensating Income Variation (CIV) equals

$$
\mathrm{CIV}=\left(y_{11}-y_{01}+\ldots+y_{1 k}-y_{0 k}\right)+\left(y_{0 m}+\ldots+y_{0 m+n}\right) .
$$

The first term at the right hand is the compensating income variation measure to compensate for a health loss. The second term represents the compensating income variation to compensate for a falling life expectancy. ${ }^{4}$

This model forms the essence for our empirical application where we will estimate the compensating income variation (CIV) for having a cardiovascular disease (CVD). In what follows, we will estimate a utility function $U(y, h ; x)$ where $y$ is annual income, $h$ is dummy which equals one if the individual is a heart patient and zero otherwise, and $x$ is a vector of intervening variables like age. This enables us to calculate the first part of (2.5). Making use of Dutch health statistics, we are able to find the compensation needed for the remaining life years.

\section{Estimating an extended Leyden welfare func- tion}

We will use the method of welfare measurement initiated by Van Praag (1968, 1971) and Van Praag and Kapteyn (1973) to calculate the compensating income variation. We present a brief outline of this so-called Leyden welfare function. ${ }^{5}$

\subsection{Leyden welfare}

The notion that nearly all individuals are able to evaluate their situation in relative terms by positioning it somewhere between a 'worst' situation and a 'best' situation has been adopted by the Leyden school. The empirical literature around the Leyden welfare function of income (WFI) is based on a specific attitude question. This question is called the Income Evaluation Question or IEQ (Van Praag, 1971) and runs as follows:

\footnotetext{
${ }^{4}$ Now we implicitly assign monetary values equal to 0 to the status of death during $n$ remaining years. This means that for our new utility function $V$ equality $V(0)=0$ has to hold which clearly puts some additional structure on our annual utility function.

${ }^{5}$ The following description of the Leyden welfare function is partially taken from Plug, Van Praag and Hartog (1999). As this paper is intended to another readership, which is probably not familiar with the Leyden method, we think it makes sense to include this section in the paper.
} 
Which monthly household after tax income would you in your circumstances consider to be very bad? Bad? Insufficient? Sufficient? Good? Very good?
About $€ \ldots \ldots . .$. very bad.
About $€ \ldots \ldots$....bad.
About $€ \ldots . . . .$. insufficient.
About $€ \ldots . . . .$. sufficient.
About $€ \ldots . . . .$. good.
About $€ \ldots . . . .$. very good.

The answers of the IEQ are denoted as $c_{1}, c_{2}, c_{3}, c_{4}, c_{5}$ and $c_{6}$. If we accept that the answers linked to the verbal qualifiers "very bad, bad, insufficient, sufficient, good" and "very good" are evaluations of welfare derived from these various income levels, the IEQ gives us six points on an individual welfare function (Van Praag, 1991). The Equal Interval Assumption (Van Praag, 1971) translates these verbal qualifications on a numerical scale

$$
U\left(c_{k}\right)=\frac{2 k-1}{12}
$$

where $k$ runs from 1 to 6 . The fact that the labels are placed equidistant from one another is examined in Buyze (1982) and Van Praag (1991). Both test the Equal Interval Assumption and do not reject it. It is interesting to notice that in the experimental psychology literature Parducci (1995) advocates the same Equal Interval Assumption. On theoretical and empirical grounds $U(y)$ is approximated by a lognormal distribution function (Van Praag, 1968,1991; Van Herwaarden and Kapteyn, 1981). Then, utility can be written as

$$
U(y)=\Lambda(y ; \mu, \sigma)=N\left(\frac{\ln y-\mu}{\sigma} ; 0,1\right)
$$

where $\Lambda$ stands for the lognormal distribution function, $N$ stands for the standard normal distribution function. The welfare parameter $\mu$ is estimated by

$$
\mu=\frac{1}{6} \sum_{k=1}^{6} \ln c_{k} .
$$

The parameter $\sigma^{2}$ is estimated analogously by

$$
\sigma^{2}=\frac{1}{5} \sum_{k=1}^{6}\left(\ln c_{k}-\mu\right)^{2} .
$$

Since the IEQ clearly states that answers have to be given "in your circumstances" the welfare function is measured conditional on these circumstances. The two welfare parameters are also conditionally measured and we therefore assume $\mu$ and $\sigma$ to vary over individuals and households.

The traditional explanation for differences in $\mu$ is that families with different net family incomes $y$ and family sizes $f s$ will respond differently to the Income 
Evaluation Question. Family size is included because children within the household create costs and therefore influence perceived welfare. That is, a family of six will need a higher income to obtain a certain welfare level than a family of four, other things being equal. Income is included to reflect the way people adapt their income judgment to changes in their current income. This is referred to as preference drift (Van Praag, 1971). The following relationship has been shown to hold

$$
\mu=\beta_{0}+\beta_{1} \ln f_{s}+\beta_{2} \ln y .
$$

This method has yielded stable and consistent results covering two decades, many countries and many populations. Our results presented in Table 2 form no exception. With respect to the parameter $\sigma$, it turns out that it is not so easy to explain. In this paper we will continue and treat $\sigma$ is a random variable in our the sample. With respect to our further calculations, we set it as a constant at the sample average (see Hagenaars, 1986).

\subsection{The data}

For our analysis we use the 1995 wave of the Supplementary Provision Survey (SPS, Aanvullend Voorzieningengebruik Onderzoek 1987, 1995) of the Dutch Social and Cultural Planningbureau (SCP). The SPS is a random national crosssectional survey consisting of over 14,000 observations at the individual level. The main purpose of the survey is to monitor the use of publicly subsidized goods and services. It also contains information about individual characteristics. The SPS is conducted every four years. For each new wave a new cross-section of the population is interviewed. From this data set we have selected individuals aged 18 and older.

In the latest edition the questionnaire included the Income Evaluation Question. In this paper 8,030 welfare functions could be identified when we restricted ourselves to fully answered IEQ's where the answers are strictly increasing in order. Missing observations on household income reduces the sample further to 7,131 individuals. If we correct for extreme IEQ-response behavior by assuming that "normal" response behavior satisfies

$$
0.01 \leq N\left(\frac{\ln y-\mu}{\sigma}\right) \leq 0.99
$$

we have 6,727 observations that remain in the sample. In other words, "normal" respondents evaluate their own after tax income $y$ between the values 0.01 and 0.99 on a $[0,1]$-scale. This mechanism simultaneously corrects for possible measurement errors in income or IEQ answers. Missing values on variables concerning schooling, gender, household composition and health status are excluded. Schooling is measured in years of schooling, gender is a dummy variable that equals one for females, household composition is represented by the number of household members and health status is a dummy variable that indicates whether people experienced a cardiovascular disease recently. We end up with 
a sample consisting of 6,382 observations. Descriptive statistics appear in Table 1.

\subsection{Cardiovascular disease and Leyden welfare}

Returning to the traditional $\mu$ parameter in (3.4) it is obvious that family size and income do not exhaust the set of explanatory variables. And indeed, in a recent study Plug, van Praag and Hartog (1999) it is found that within the Leyden methodology also education and IQ matter. They conclude that both education and IQ raise needs. The new variable of interest in the context of this paper is the health variable indicating whether or not an individual experienced a cardiovascular disease. Given the impact of aforementioned factors on $\mu$, we assume that the capacity to derive welfare (satisfaction) from income is affected by the health of an individual. We expect that having a cardiovascular disease lowers welfare, and that the sign of its effect on $\mu$ will be positive.

Estimation results are presented in Table 2. In the first column we estimate the relation between $\mu$ and the aforementioned variables without our CVD measure. We find the usual income and family size effects. The former is the well established preference drift effect. As stated earlier, there is a welfare leakage because part of additional income increases aspirations as well. A preference drift of 50 percent and a family size elasticity of 7 percent are fully in line with the results commonly found. We see that the effect of education is highly significant. With schooling more income is needed to attain a given welfare level; it seems that schooling raises household needs. The age variables account for life cycle effects. In the beginning of life there is the need to accumulate wealth in order to provide for anticipated expenditures at a later age. We find maximum needs at the age of 48 years old. We also find that gender matters with respect to welfare evaluations, but that its effect in size is relatively small.

In the second column we turn to our new variable of interest and bring the health variable into the equation. The CVD parameter turns out to be positive, which corresponds with the idea that having a cardiovascular disease creates a fall in experienced welfare, but its effect is statistical significant at the 10 percent level only. This is probably a matter of cell size. Our estimate is based on a small sample of observations of 154 people reporting a CVD.

If age is a factor that mitigates the impact of a CVD on welfare, we need to include the interacted CVD $\times$ age effect. This is done in the third and final column in Table 2. The interaction effect is negative which indicates that the welfare loss is substantially larger for younger patients. This finding is consistent with the idea that a CVD at a younger age is much more of an impediment to the normal life that an older age. At the end of the life cycle, around the age of 80 , we find that welfare losses due to a CVD become negligible. The impact of CVD and its interaction turn out to be jointly significant at the 10 percent level. 


\subsection{Cardiovascular disease and family income}

Health affects welfare that people derive from their income in two separate ways. The first effect arises because the perception of welfare is directly influenced by health. The second effect is that health also affects the capacity to earn income. Because income is an essential input in an individual's welfare function, welfare is indirectly influenced by health through income. In the empirical implementation of the model we account for this by estimating the coefficients in the income equation. Estimation results are given in Table 3. Table 3 is similarly structured as Table 2 . In the first column we start with our baseline family income equation and find conventional results. We find a significant gender effect. The education elasticity turns out to be close to 35 percent. Age effects follow the standard experience profile; maximum income is found at the age of 42 years old.

In the second column our CVD variable enters the income equation and we observe that people who experienced a cardiovascular disease income receive about 7 percent less income. In the third column we allow for age depended health effects and find that the impact of having a cardiovascular disease is strongest when people are young. At the age of 85 , which corresponds closely to observed life expectancies, the CVD impact on income has disappeared. Again, the CVD and interacted CVD parameters are jointly significant. ${ }^{6}$

\section{Calculating the compensating income varia- tion of a cardiovascular disease}

If we return to $(2.5)$ we see that the amount to compensate an individual for having a cardiovascular disease consists of two parts. The first part is the amount to compensate for the welfare loss because health deteriorated from $h_{0}$ to $h_{1}$. The second part is the amount to compensate for the loss in years to live. With an empirical representation of welfare function, we are able to calculate this first part of the compensating income variation.

\subsection{Compensating variation to compensate for the losses in welfare}

How does a cardiovascular disease affect welfare? With help of our results of Table 2 and 3 we are able to shed light on this question. Within the Leyden welfare methodology which is frequently applied to study the effects of children

\footnotetext{
${ }^{6}$ Rather than estimating income in the traditional Mincerian way, we have chosen to estimate household income as a double logarithmic equation. We feel excused to deviate for three reasons. First, in our model it is more convenient to use this particular specification. Second, even when we use the more traditional Mincerian or semilogarithmic specification, the corresponding value of measures and compensating variations are almost identical to the findings reported in Tables 4, 5, 7 and 9. And third, like us others (Heckman and Polachek, 1974; Hirschberg and Slottje, 1996) have studied this alternative household income function and find that the double logarithmic specification is not rejected by the data.
} 
on welfare (Van Praag and Kapteyn, 1973; Plug and Van Praag, 1995; Van Praag and Warnaar, 1997) welfare effects are usually expressed in terms of equivalence scales. In this Section we will express the effects of a CVD on welfare in terms of equivalence scales.

Let's say that income $y$ only depends on health $h$, and that welfare parameter $\mu$ only depends on income $y$ and health $h$, then we can write down the following expressions

$$
\ln y=\alpha_{0}+\alpha_{1} h, \text { and } \mu=\beta_{0}+\beta_{1} h+\beta_{2} \ln y .
$$

If $z$ is the equivalence scale, it is easy to see that two individuals with different health conditions $h_{0}$ and $h_{1}$ enjoy equal welfare if, and only if,

$$
U\left(y\left(h_{0}\right)\right)=U\left(z y\left(h_{1}\right)\right) .
$$

Translated into equivalence in terms of Leyden welfare, this means

$$
\ln y\left(h_{0}\right)-\mu\left(y\left(h_{0}\right)\right)=\ln z y\left(h_{1}\right)-\mu\left(z y\left(h_{1}\right)\right)
$$

where $\sigma$ is assumed constant. Keeping everything else constant, substitution of previous equations in (4.1) yields

$$
\left(1-\beta_{2}\right) \alpha_{1} h_{0}-\beta_{1} h_{0}=\left(1-\beta_{2}\right) \ln z+\left(1-\beta_{2}\right) \alpha_{1} h_{1}-\beta_{1} h_{1}
$$

which gives us the solution

$$
\ln z=-\alpha_{1}\left(h_{1}-h_{0}\right)+\frac{\beta_{1}}{1-\beta_{2}}\left(h_{1}-h_{0}\right) .
$$

We interpret the second term at the right hand side as the direct effect, while the first term reflects the indirect effect. The direct equivalence effect reflects the equivalence scale proper: additional income is needed for people with a CVD in order to maintain welfare. The indirect effect reflects the fact that an individual with a CVD earns on average $\alpha_{1}$ less: it's the labour market's punishment to an individual's welfare, which is added to the former equivalence effect.

Table 4 presents both welfare effects associated with the net earnings function and welfare function given in the final column of Tables 2 and 3. The first column shows that a 25 year old individual with a CVD would need about 43 percent more income to be as well off as a healthy individual of the same age. The second column shows that the labour market rewards those who are healthy and punishes those who are sick. For a 25 year old individual we find that a CVD creates a 40 percent reduction in income. If we combine these direct and indirect welfare effects, we find that a CVD at age 25 requires income to increase by 100 percent to maintain the same welfare level as a healthy individual of the same age. The same table shows that for each age category individuals with a CVD need more income than healthier individuals. They need to be compensated because a CVD makes them less satisfied with their income for any given income level, but also because a CVD makes them earn less. We also observe that these compensations vary with age and fall with rising age. At the end of 
the life cycle at the age of 75 these compensations are small but still positive. At age 80 all effects turn out to be negligible.

Equivalence scales identify these compensations in relative terms $y_{1} / y_{0}$. To get an idea of the magnitude in absolute terms, we report the belonging compensating income variations per year in Table 5 . These amounts $y_{1}-y_{0}$ are calculated for three consecutive welfare levels sufficient, good and very good. For our reference individual, we take healthy individuals with a higher vocational education, registered as being married with no kids. If we assume that people who suffer from a CVD receive treatment and recover completely the next period, the monetary amounts in Table 5 represent the CIV amounts to compensate people for their welfare losses created by having a CVD. The effects we find in Table 5 correspond closely to the effects we observed in Table 4 . We further see that the compensating variations for 35 year old patients range from $€ 8,500$ up to $€ 23,000$, increase with the welfare level, decrease slightly with age, and are somewhat smaller for women.

\subsection{Compensating variation to compensate for the losses in life expectancy}

A diagnosed CVD patient also experiences a loss in lifetime utility because of a falling life expectancy. To calculate the monetary equivalent of this particular utility loss, we require information on the patient's remaining years to live, and the number of years by which his or her life expectancy is shortened. In our model $m$ and $n$ correspond to these values. Because our sample does not provide information on $m$ and $n$, we rely on Dutch health statistics to find suitable values for the remaining life years.

To identify life expectancies $(m+n)$ we borrow from Statistics Netherlands (CBS, 1995) and report the corresponding values in Table 6 . We find that life expectancies depend on age and increase when people get older. To identify falling life expectancies $(n)$ we borrow from Van Ginneken, Bannenberg and Dissevelt (1989). In their study the expected gain in life years by complete elimination of the health risk because of a CVD is calculated for men and women of different ages. These gains in life years are also presented in Table 6 . We find that a 25 year old male without a CVD has 13.29 additional years to live. For an equally old women this amounts to 11.62 additional years. Table 6 shows further that expected gains in years to live fall with rising age, and that this age dependent fall is much smaller for women.

Again, with the Leyden welfare function we identify the annual monetary equivalence belonging to three different welfare levels sufficient, good and very good for healthy individuals with a higher vocational education, registered as being married with no kids. We then start with adding the annual monetary amounts up from age $m+1$ onwards and stop when we reach age $m+n$.

In Table 7 we report these amounts. We find that the compensating variations are much higher than the compensations reported in Table 5. We further see that the CIVs increase with the welfare level, decrease slightly with age, and are smaller for women. Two separate factors explain the gender gap. In the 
beginning of the lifecycle compensations are lower because women face a smaller loss in their life expectancy than men when diagnosed a CVD patient. And at the end of the lifecycle compensations are lower because women live longer than men and thus need less money to be equally well off as relatively younger men.

\subsection{Compensating variation and cardiovascular diseases}

Now that we have all the ingredients we can calculate the compensating income variation for having a cardiovascular disease. The amounts to compensate for the welfare loss induced by having a CVD are tabulated in Table 5. The amounts to compensate for the loss in additional years to live due to a CVD are tabulated in Table 7 . Together they form the compensating income variation for a diagnosed CVD patient. In Table 8 we operationalize these CIVs.

The first entry shows that a diagnosed CVD patient who is male and 25 years old needs in total about $€ 160,000$ to be as well off as he was before the CVD and lived a life of sufficient quality. ${ }^{7}$ To reach higher welfare levels, the same patient requires more money. Compared to sufficient, we have to give the same patient almost $€ 430,000$ to maintain a welfare level that is very good. When he is 65 years old, the hazards and troubles of a CVD require smaller compensations. This time about $€ 100,000$ to $€ 260,000$ are needed to make him as well off as he was before. We find in general that all CIVs fall with age. We also find that the CIV amounts for female patients are almost always lower than the amounts for equivalent male patients. This again was expected given the argument that women almost always face smaller losses in their life expectancy when diagnosed a CVD patient. When we translate these CIV numbers into compensating values for each additional year gained, we find that the annual CIV amounts remain to fall with rising age, but this time the gender gap is disappeared. The estimated amounts vary between about $€ 8,000$ to $€ 32,000$.

These final CIV estimates are relevant for cost-effectiveness or cost-utility analysis of medical interventions, particularly for heart related interventions. QALYs measure the amount of healthy years gained by a medical intervention and, when combined with the costs of such an intervention, can be used to calculate how much money has to be spent on a medical intervention per QALY. These amounts can be used to rank medical interventions by their effectiveness. Although this procedure allows us to determine which intervention provides more value for money, it does not provide information on which intervention should be funded and which interventions are no longer cost-effective. To determine which kind of interventions is efficient, we need information on how much an intervention is worth to the patient him or herself.

Heart transplantations in the Netherlands cost on average $€ 32,000$ but vary from $€ 26,000$ to $€ 42,000$ per quality adjusted life years (Van Hout et al, 1993). Dutch estimates for the costs for open-heart surgery vary from $€ 10,000$ to

\footnotetext{
${ }^{7}$ Note that a life of sufficient quality refers to the level of income satisfaction and not to quality of life as a whole. This latter approach is recently taken up by Groot and Maassen van den Brink (1999) and Ferrer-i-Carbonell and Van Praag (2002).
} 
$€ 30,000$ for each additional healthy year lived while estimates for bypass treatments range from $€ 2,500$ to $€ 20,000$ (Adang, 1998). At first sight, the confrontation between our treatment calculations and the cost effectiveness seem to justify most bypass and open heart surgery treatments. Heart transplants seem to be too costly and only efficient if patients are young. For definite answers, however, more research with more detailed information on the type of vascular diseases is necessary.

We should be careful when interpreting these results. The estimates we presented are based on a number of assumptions. Changing these assumptions will directly affect our estimates. We consider two potential limitations of our approach and test how sensitive our CIV estimates are if we use alternative and maybe more realistic assumptions. First, we assumed that individuals did not discount their future income and estimated our variations in absence of positive time discounting. If we would allow for personal discounting we end up with lower compensations because the importance of future income for today's lifetime utility has decreased. Second, we hypothesized that patients who suffered from a cardiovascular disease fully recovered the year after the incident and faced shortened life expectancies. But if we would accept that diagnosed people face higher probabilities of being diagnosed again, we end up with higher compensations because the sequelae of CVD events would lead to corresponding losses in welfare that need to compensated as well.

In Table 9 we operationalize the final CIVs and include a sensitivity analysis regarding these two limitations. We allow for discounting and calculate the CIVs for three different personal discount rates set at 0,5 and 25 percent. These discount rates are taken from existing literature. For example, Warner and Pleeter (2001) estimate personal discount rates and find that their estimates range from 0 to 30 percent. We allow for alternative CVD histories and experiment with patients who recover completely in one year, in two years and finally patients who do not recover at all. The first three columns represent the CIVs for patients who do not discount their future income and up with the amounts from our baseline model expressed earlier in Table 8. The second three columns represent the CIVs for patients with discount rates of 5 percent. The estimated amounts fall and range from $€ 7,000$ to $€ 25,000$. The final three columns represent CIVs for patients with high discount rates, and again, we find lower amounts ranging from $€ 4,000$ to $€ 13,500$. On the basis of these results, we would conclude that heart transplants can no longer be justified, but bypass treatments and open heart surgery could still be possible in terms of efficiency.

\section{Conclusion}

Cost-effectiveness and cost-utility estimates play an increasingly important role in decisions about the adoption of new medical technology. Limitations on financial resources and the increasing costs of new medical technologies force governments and health care insurance companies to make more 'rational' decisions about which treatments are reimbursed and which are not. The rising costs 
of health care raises the question whether we are spending too much on health care. In order to answer this question we need to know how much value individuals put on their health. This paper contributes to answering this question by introducing a new method to calculate the compensating variation belonging to the elimination of the health impairments associated with heart diseases: the Leyden Income Evaluation approach.

It is found that for a 25 year old male the compensating variation of a heart disease ranges from $€ 160,000$ to $€ 430,000$ depending on the welfare level. This is about $€ 8,000$ to $€ 32,000$ for an additional life year, again depending on the quality of life. The compensating variation declines with age and is lower for women than for men. The estimates further vary by the discount rate chosen. The estimates of the compensating variation are generally higher than the money spend on most heart related medical interventions per QALY. Compared to the money spend on medical interventions per QALY the estimated benefits of the elimination of heart problems seem to justify these medical treatments.

The Leyden income evaluation method avoids some of the drawbacks and pitfalls of other methods. It also has the advantage that it can be applied at low costs to many different situations. In particular we think that a fruitful topic for further research would be to calculate the WFI before and after a medical intervention in order to determine the monetary value of the gain in welfare because of medical treatment.

\section{References}

Adang, E. 1998, Medical technology assessment in surgery. PhD thesis, University of Maastricht.

Buyze, J. 1982, The estimation of welfare levels of a cardinal utility function. European Economic Review, 17, 325-332.

CBS, 1995. Vijfennegentig jaren statistiek in tijdreeksen 1899-1994. (Historical series of the Netherlands 1899-1994), The Hague, SDU Publishers.

Diener, A., B. O'Brien and A. Gafni. 1998. Health care contingent valuation studies: a review and classification of the literature, Health Economics 7, 313-326.

Ferrer-i-Carbonell, A. and B.M.S. Van Praag. 2002. The subjective costs of health losses due to chronic diseases. An alternative model for monetary appraisal, Health Economics, forthcoming.

Groot, W. and H. Maassen van den Brink. 1999. The willingness to pay for migraine headache, paper presented at Health Economics Workshop at Bergen University, Norway, May 26-27, 2000. 
Hagenaars, A.J.M. 1986. The perception of poverty. Amsterdam, North-Holland.

Hagenaars, A.J.M. and B.M.S. Van Praag. 1985, A synthesis of poverty line definitions. Review of Income and Wealth, 31, 139-153.

Heckman, J. and S. Polacheck. 1974. Empirical evidence on the functional form of earnings-schooling relationship. Journal of American Statistical Association, 69, 350-354.

Hirschberg, J.G. and D.J. Slottje. 1996. The sensitivity of functional forms of earnings functions to specification. Journal of Income Distribution, 6, 1, 2435 .

Kenkel, D. 1997. On valuing morbidity, cost-effectiveness analysis, and being rude. Journal of Health Economics, 16, 749-757

Labelle, R. and J. Hurley. 1992. Implications of basing health-care resource allocations on cost-utility analysis in the presence of externalities. Journal of Health Economics, 11, 259-277.

Mishan, E. 1988. Cost-Benefit Analysis: an Informal Introduction. Unwin Heyman, London.

Parducci, A. 1995. Happiness, pleasure and judgment, New Jersey, Lawrence Erblaum Associates, Publishers.

Plug, E.J.S. and B.M.S. Van Praag. 1995, Family equivalence scales within a narrow and broad welfare context. Journal of Income Distribution, 4, 171-186.

Plug, E.J.S. and B.M.S. Van Praag. 1998, Similarity in response behavior between household members: An application to income evaluation. Journal of Economic Psychology, 19, 497-513.

Plug, E.J.S., B.M.S Van Praag and J. Hartog. 1999, If we knew ability, how would we tax individuals? Journal of Public Economics, 72, 183-211.

Van de Stadt, H., A. Kapteyn and S. Van de Geer. 1985, The relativity of utility: Evidence from panel data. The Review of Economics and Statistics, 67, 179-187.

Van Ginneken, J.K.S., A.F.I. Bannenberg and A.G. Dissevelt. 1989, Gezondheidsverlies ten gevolge van een aantal belangrijke ziektecategorieen in 1981-1985. (Loss in health due to a number of important illnesses), Dutch Central Bureau of Statistics, Voorburg.

Van Herwaarden, F.G. and A. Kapteyn. 1981. Empirical comparison of the 
shape of welfare functions. European Economic Review, 15, 261-286.

Van Hout, B., G. Bonsel, D. Habbema, P. Van der Maas and F.de Charro. 1993, Heart transplantation in the Netherlands; Costs, effects and scenarios, Journal of Health Economics, 12, 73-93.

Van Praag, B.M.S. 1968, Individual welfare functions and consumer behavior, Amsterdam, North-Holland.

Van Praag, B.M.S. 1971, The welfare function of income in Belgium: An empirical investigation, European Economic Review, 2, 337-369.

Van Praag, B.M.S. 1991, Ordinal and cardinal utility: An integration of the two dimensions of the welfare concept, Journal of Econometrics, 50, 69-89.

Van Praag, B.M.S. and A. Kapteyn. 1973. Further evidence on the individual welfare function of income: An empirical study in the Netherlands, European Economic Review, 4, 33-62.

Van Praag, B.M.S. and M. Warnaar. 1997. The Cost of Children and the Effects of Demographic Variables on Consumer Demand. In Rosenzweig, M.R. and O. Stark, editors, The Handbook of Population and Family Economics. Amsterdam, North-Holland.

Van Praag, B.M.S., Th. Goedhart and A. Kapteyn. 1980, The poverty line: A pilot survey in Europe. The Review of Economics and Statistics, 62, 461-465.

Warner, J.T. and S. Pleeter. 2001, The personal discount rate: Evidence from military downsizing programs. The American Economic Review, 91, 33-53

Viscusi, W. Kip. 1993. The value of risks to life and health. Journal of Economic Literature, 31, 1912-1946.

Viscusi, W. Kip. 1997. Rational Risk Policy. Oxford Economic Press, Oxford. 
Table 1: Descriptive statistics of selected variables in SPS sample

\begin{tabular}{|c|c|c|c|c|}
\hline & means & $\begin{array}{l}\text { standard } \\
\text { deviation }\end{array}$ & minimum & maximum \\
\hline \multicolumn{5}{|l|}{ variables } \\
\hline female & 0.513 & 0.499 & 0.000 & 1.000 \\
\hline age & 45.009 & 15.575 & 18.000 & 94.000 \\
\hline years of schooling & 10.840 & 3.942 & 6.000 & 17.000 \\
\hline household size & 2.651 & 1.298 & 1.000 & 11.000 \\
\hline monthly household income & 1570.056 & 748.067 & 544.536 & 3970.557 \\
\hline cardiovascular disease & 0.024 & 0.153 & 0.000 & 1.000 \\
\hline$\mu$ & 7.827 & 0.347 & 6.288 & 9.309 \\
\hline$\sigma$ & 0.410 & 0.182 & 0.052 & 2.410 \\
\hline$N$ & 6382 & & & \\
\hline
\end{tabular}

Household income is measured in Euros $(€)$.

Table 2: Estimates of the Leyden welfare function: three specifications

\begin{tabular}{lrlrlrl}
\hline \hline intercept & 0.885 & $0.336^{* * *}$ & 0.830 & $0.338^{* *}$ & 0.901 & $0.341^{* * *}$ \\
log household size & 0.067 & $0.006^{* * *}$ & 0.067 & $0.006^{* * *}$ & 0.067 & $0.006^{* * *}$ \\
log household income & 0.501 & $0.006^{* * *}$ & 0.501 & $0.006^{* * *}$ & 0.501 & $0.006^{* * *}$ \\
female & -0.014 & $0.005^{* *}$ & -0.014 & $0.005^{* *}$ & -0.013 & $0.005^{* *}$ \\
log years of schooling & 0.037 & $0.008^{* * *}$ & 0.037 & $0.008^{* * *}$ & 0.037 & $0.008^{* * *}$ \\
log age & 1.458 & $0.187^{* * *}$ & 1.489 & $0.188^{* * *}$ & 1.448 & $0.190^{* * *}$ \\
log age squared & -0.190 & $0.025^{* * *}$ & -0.194 & $0.025^{* * *}$ & -0.188 & $0.025^{* * *}$ \\
cardiovascular disease (CVD) & & & 0.031 & $0.018^{*}$ & 0.680 & 0.421 \\
CVD $\times$ log age & & & & & 0.155 & 0.101 \\
& & & & & & \\
$R^{2}$ & 0.580 & & 0.580 & & 0.581 & \\
$N$ & 6382 & & 6382 & & 6382 & \\
\hline \hline
\end{tabular}

Standard errors in italics; ${ }^{*},{ }^{* *}$ and ${ }^{* * *}$ implies significance at the $10 \%, 5 \%$ and $1 \%$ levels, respectively. The dependent variable in all three columns is the Leyden welfare parameter $\mu$. In column three the CVD and interacted CVD parameters are jointly significant. The $F$ test equals 2.614, its $p$ value is 0.073 . 
Table 3: Estimates of the family income function: three specifications

\begin{tabular}{|c|c|c|c|c|c|c|}
\hline intercept & -8.372 & $0.571^{* * *}$ & -8.244 & $0.575^{* * *}$ & -8.365 & $0.581^{* * *}$ \\
\hline female & -0.049 & $0.010^{* * *}$ & -0.050 & $0.010^{* * *}$ & -0.051 & $0.010^{* * *}$ \\
\hline log years of schooling & 0.326 & $0.015^{* * *}$ & 0.326 & $0.015^{* * *}$ & 0.325 & $0.015^{* * *}$ \\
\hline log age & 8.481 & $0.308^{* * *}$ & 8.407 & $0.310^{* * *}$ & 8.475 & $0.313^{* * *}$ \\
\hline log age squared & -1.136 & $0.041^{* * *}$ & -1.126 & $0.026^{* * *}$ & -1.135 & $0.042^{* * *}$ \\
\hline cardiovascular disease (CVD) & & & -0.072 & $0.035^{* *}$ & -1.210 & 0.788 \\
\hline $\mathrm{CVD} \times \log$ age & & & & & 0.272 & 0.188 \\
\hline$R^{2}$ & 0.199 & & 0.200 & & 0.200 & \\
\hline$N$ & 6382 & & 6382 & & 6382 & \\
\hline \multicolumn{7}{|c|}{$\begin{array}{l}\text { Standard errors in italics; }{ }^{*},{ }^{* *} \text { and }{ }^{* * *} \text { implies significance at the } 10 \%, 5 \% \text { and } 1 \% \text { levels, } \\
\text { respectively. The dependent variable in all three columns is log monthly income. In column } \\
\text { three the CVD and interacted CVD parameters turn out to be jointly significant. The } F \text { test } \\
\text { equals } 3.144 \text {, its } p \text { value is } 0.043 \text {. }\end{array}$} \\
\hline
\end{tabular}

Table 4: CVD and equivalence scales

\begin{tabular}{lccc}
\hline \hline & direct & indirect & total \\
\hline 25 years & 1.43 & 1.39 & 2.00 \\
35 years & 1.29 & 1.27 & 1.64 \\
45 years & 1.19 & 1.19 & 1.42 \\
55 years & 1.12 & 1.12 & 1.26 \\
65 years & 1.06 & 1.07 & 1.14 \\
75 years & 1.02 & 1.03 & 1.05 \\
\hline \hline
\end{tabular}

Table 5: CVD and compensations for welfare losses by gender, age and welfare level.

\begin{tabular}{lrrrrrr}
\multicolumn{1}{c}{ males } & \multicolumn{1}{c}{ females } \\
\hline \hline & \multicolumn{1}{c}{$u_{1}$} & \multicolumn{1}{c}{$u_{2}$} & \multicolumn{1}{c}{$u_{3}$} & \multicolumn{1}{c}{$u_{1}$} & \multicolumn{1}{c}{$u_{2}$} & \multicolumn{1}{c}{$u_{3}$} \\
\hline 25 years & 12,192 & 17,878 & 32,072 & 11,875 & 17,387 & 31,191 \\
35 years & 8,785 & 12,882 & 23,110 & 8,543 & 12,528 & 22,475 \\
45 years & 5,887 & 8,633 & 15,487 & 5,725 & 8,396 & 15,062 \\
55 years & 3,638 & 5,335 & 9,571 & 3,538 & 5,188 & 9,308 \\
65 years & 1,941 & 2,846 & 5,107 & 1,888 & 2,768 & 4,967 \\
75 years & 674 & 988 & 1,774 & 655 & 961 & 1,725 \\
\hline \hline
\end{tabular}

Compensating variations are annual amounts and measured in Euros $(€)$. The three welfare levels correspond to the labels "sufficient", "good" and "very good". 
Table 6: Life and gain in life expectancy by age and gender in absence of a CVD.

\begin{tabular}{lrrrr} 
& males & \multicolumn{3}{c}{ females } \\
\hline \hline & $m+n$ & \multicolumn{1}{c}{$n$} & $m+n$ & \multicolumn{1}{c}{$n$} \\
\hline 25 years & 75.15 & 13.29 & 80.80 & 11.62 \\
35 years & 75.65 & 13.22 & 81.05 & 11.56 \\
45 years & 76.30 & 12.93 & 81.55 & 11.45 \\
55 years & 77.40 & 12.12 & 82.35 & 11.15 \\
65 years & 79.75 & 10.57 & 83.90 & 10.50 \\
75 years & 83.90 & 8.31 & 86.70 & 9.02 \\
\hline \hline
\end{tabular}

These numbers come from Van Ginneken, Bannenberg and Dissevelt (1989) and Statistics Netherlands (CBS, 1995).

Table 7: CVD and compensations for life expectancy losses by gender, age and welfare level.

\begin{tabular}{lrrrrrc}
\multicolumn{1}{c}{ males } & \multicolumn{5}{c}{ females } \\
\hline \hline & \multicolumn{1}{c}{$u_{1}$} & \multicolumn{1}{c}{$u_{2}$} & $u_{3}$ & $u_{1}$ & $u_{2}$ & $u_{3}$ \\
\hline 25 years & 150,985 & 221,400 & 397,183 & 131,304 & 192,541 & 345,412 \\
35 years & 141,617 & 207,663 & 372,539 & 123,039 & 180,421 & 323,669 \\
45 years & 133,417 & 195,640 & 350,970 & 105,256 & 154,344 & 276,888 \\
55 years & 114,912 & 168,503 & 302,289 & 99,098 & 145,315 & 260,690 \\
65 years & 97,112 & 142,402 & 255,465 & 83,573 & 122,549 & 219,848 \\
75 years & 64,389 & 94,418 & 169,383 & 69,417 & 101,792 & 182,611 \\
\hline \hline
\end{tabular}

Compensating variations are measured in Euros $(€)$. The three welfare levels correspond to labels "sufficient", "good" and "very good". 
Table 8: Compensations for diagnosed CVD patients by gender, age and welfare level.

\begin{tabular}{|c|c|c|c|c|c|c|}
\hline & \multicolumn{3}{|l|}{ males } & \multicolumn{3}{|l|}{ females } \\
\hline & $u_{1}$ & $u_{2}$ & $u_{3}$ & $u_{1}$ & $u_{2}$ & $u_{3}$ \\
\hline \multicolumn{7}{|c|}{ compensations: } \\
\hline 25 years & 163,177 & 239,279 & 429,256 & 143,162 & 209,929 & 376,604 \\
\hline 35 years & 150,402 & 220,546 & 395,650 & 131,584 & 192,950 & 346,146 \\
\hline 45 years & 139,305 & 204,274 & 366,459 & 110,982 & 162,741 & 291,951 \\
\hline 55 years & 118,550 & 173,839 & 311,860 & 102,637 & 150,504 & 269,998 \\
\hline 65 years & 99,054 & 145,250 & 260,572 & 85,461 & 125,318 & 224,815 \\
\hline 75 years & 65,064 & 95,408 & 171,157 & 70,074 & 102,754 & 184,337 \\
\hline \multicolumn{7}{|c|}{ compensations for each additional year gained: } \\
\hline 25 years & 12,278 & 18,004 & 32,299 & 12,320 & 18,066 & 32,410 \\
\hline 35 years & 11,377 & 16,683 & 29,928 & 11,383 & 16,691 & 29,943 \\
\hline 45 years & 10,782 & 15,811 & 28,364 & 9,693 & 14,213 & 25,498 \\
\hline 55 years & 9,781 & 14,343 & 25,731 & 9,205 & 13,498 & 24,215 \\
\hline 65 years & 9,371 & 13,742 & 24,652 & 8,139 & 11,935 & 21,411 \\
\hline 75 years & 7,830 & 11,481 & 20,597 & 7,769 & 11,392 & 20,436 \\
\hline
\end{tabular}


Table 9: Compensations for CVD for each additional year lived in good health by gender, age, welfare level, recovery period and discount factors.

\begin{tabular}{|c|c|c|c|c|c|c|c|c|c|}
\hline \multirow[t]{2}{*}{ males } & \multicolumn{3}{|c|}{ no discounting $(0)$} & \multicolumn{3}{|c|}{ low discounting (5\%) } & \multicolumn{3}{|c|}{ high discounting $(25 \%)$} \\
\hline & $u_{1}$ & $u_{2}$ & $u_{3}$ & $u_{1}$ & $u_{2}$ & $u_{3}$ & $u_{1}$ & $u_{2}$ & $u_{3}$ \\
\hline \multicolumn{10}{|c|}{ recovery period 1 year: } \\
\hline 25 years & 12,278 & 18,004 & 32,299 & 9,458 & 13,869 & 24,880 & 5,112 & 7,496 & 13,447 \\
\hline 35 years & 11,377 & 16,683 & 29,928 & 8,719 & 12,785 & 22,936 & 4,622 & 6,777 & 12,158 \\
\hline 45 years & 10,782 & 15,811 & 28,364 & 8,220 & 12,054 & 21,624 & 4,271 & 6,263 & 11,236 \\
\hline 55 years & 9,781 & 14,343 & 25,731 & 7,590 & 11,130 & 19,966 & 4,032 & 5,913 & 10,607 \\
\hline 65 years & 9,371 & 13,742 & 24,652 & 7,409 & 10,864 & 19,490 & 4,048 & 5,936 & 10,648 \\
\hline 75 years & 7,830 & 11,481 & 20,597 & 6,611 & 9,695 & 17,392 & 4,138 & 6,068 & 10,885 \\
\hline \multicolumn{10}{|c|}{ recovery period 2 years: } \\
\hline 25 years & 13,170 & 19,312 & 34,644 & 10,305 & 15,111 & 27,108 & 5,825 & 8,542 & 15,323 \\
\hline 35 years & 12,017 & 17,622 & 31,613 & 9,327 & 13,677 & 24,536 & 5,134 & 7,529 & 13,506 \\
\hline 45 years & 11,218 & 16,450 & & & & 22,714 & 4,620 & & 12,154 \\
\hline 55 years & 10,066 & 14,760 & 26,479 & 7,860 & 11,526 & 20,677 & 4,260 & 6,246 & 11,206 \\
\hline 65 years & 9,541 & 13,991 & 25,099 & 7,570 & 11,101 & 19,915 & 4,184 & 6,135 & 11,006 \\
\hline 75 years & 7,898 & 11,581 & 20,776 & 6,676 & 9,790 & 17,563 & 4,193 & 6,148 & 11,029 \\
\hline \multicolumn{10}{|c|}{ recovery period $m$ years: } \\
\hline 25 years & 31,726 & 46,523 & 83,460 & 19,333 & 28,349 & 50,857 & 8,272 & 12,129 & 21,760 \\
\hline 35 years & 23,189 & 34,003 & 61,001 & 15,247 & 22,358 & 40,110 & 6,836 & 10,025 & 17,984 \\
\hline 45 years & 17,344 & 25,433 & 45,626 & 12,224 & 17,925 & 32,157 & 5,740 & 8,417 & 15,100 \\
\hline 55 years & 13,028 & 19,104 & 34,272 & 9,804 & 14,376 & 25,789 & 4,948 & 7,255 & 13,015 \\
\hline 65 years & 10,676 & 15,655 & 28,085 & 8,406 & 12,327 & 22,114 & 4,541 & 6,659 & 11,945 \\
\hline 75 years & 8,044 & 11,796 & 21,162 & 6,803 & 9,976 & 17,896 & 4,270 & 6,262 & 11,233 \\
\hline
\end{tabular}

\begin{tabular}{|c|c|c|c|c|c|c|c|c|c|}
\hline \multirow[t]{2}{*}{ females } & \multicolumn{3}{|c|}{ no discounting $(0)$} & \multicolumn{3}{|c|}{ low discounting (5\%) } & \multicolumn{3}{|c|}{ high discounting (25\%) } \\
\hline & $u_{1}$ & $u_{2}$ & $u_{3}$ & $u_{1}$ & $u_{2}$ & $u_{3}$ & $u_{1}$ & $u_{2}$ & $u_{3}$ \\
\hline \multicolumn{10}{|c|}{ recovery period 1 year: } \\
\hline 25 years & 12,320 & 18,066 & 32,410 & 9,708 & 14,235 & 25,537 & 5,466 & 8,016 & 14,380 \\
\hline 35 years & 11,383 & 16,691 & 29,943 & 8,922 & 13,084 & 23,471 & 4,928 & 7,226 & 12,964 \\
\hline 45 years & 9,693 & 14,213 & 25,498 & 7,729 & 11,334 & 20,333 & 4,367 & 6,403 & 11,487 \\
\hline 55 years & 9,205 & 13,498 & 24,215 & 7,307 & 10,714 & 19,221 & 4,056 & 5,947 & 10,669 \\
\hline 65 years & 8,139 & 11,935 & 21,411 & 6,583 & 9,654 & 17,319 & 3,768 & 5,526 & 9,913 \\
\hline 75 years & 7,769 & 11,392 & 20,436 & 6,409 & 9,398 & 16,860 & 3,805 & 5,579 & 10,009 \\
\hline \multicolumn{10}{|c|}{ recovery period 2 years: } \\
\hline 25 years & 13,312 & 19,520 & 35,018 & 10,650 & 15,616 & 28,015 & 6,260 & 9,179 & 16,466 \\
\hline 35 years & 12,095 & 17,736 & 31,817 & 9,599 & 14,076 & 25,251 & 5,498 & 8,062 & 14,463 \\
\hline 45 years & 10,171 & 14,915 & 26,757 & 8,184 & 12,001 & 21,529 & 4,749 & 6,964 & 12,494 \\
\hline 55 years & 9,506 & 13,939 & 25,006 & 7,592 & 11,133 & 19,972 & 4,296 & 6,300 & 11,301 \\
\hline 65 years & 8,306 & 12,179 & 21,849 & 6,742 & 9,886 & 17,735 & 3,902 & 5,721 & 10,264 \\
\hline 75 years & 7,830 & 11,481 & 20,597 & 6,467 & 9,483 & 17,012 & 3,854 & 5,651 & 10,138 \\
\hline \multicolumn{10}{|c|}{ recovery period $m$ years: } \\
\hline 25 years & 34,148 & 50,073 & 89,829 & 20,705 & 30,362 & 54,468 & 8,981 & 13,169 & 23,625 \\
\hline 35 years & 24,673 & 36,180 & 64,906 & 16,201 & 23,756 & 42,618 & 7,391 & 10,838 & 19,443 \\
\hline 45 years & 17,055 & 25,010 & 44,866 & 12,154 & 17,822 & 31,971 & 5,978 & 8,766 & 15,727 \\
\hline 55 years & 12,754 & 18,702 & 33,550 & 9,682 & 14,198 & 25,470 & 5,024 & 7,367 & 13,216 \\
\hline 65 years & 8,941 & 13,111 & 23,521 & 7,427 & 10,891 & 19,538 & 4,249 & 6,231 & 11,178 \\
\hline 75 years & 7,829 & 11,481 & 20,596 & 6,505 & 9,538 & 17,112 & 3,911 & 5,735 & 10,289 \\
\hline
\end{tabular}

Compensating variations are measured in Euros $(€)$. The three levels correspond to labels "sufficient", "good" and "very good". 


\section{IZA Discussion Papers}

\begin{tabular}{|c|c|c|c|c|}
\hline No. & Author(s) & Title & Area & Date \\
\hline 637 & $\begin{array}{l}\text { H. Bonin } \\
\text { W. Kempe } \\
\text { H. Schneider }\end{array}$ & $\begin{array}{l}\text { Household Labor Supply Effects of Low-Wage } \\
\text { Subsidies in Germany }\end{array}$ & 3 & $11 / 02$ \\
\hline 638 & $\begin{array}{l}\text { L. McLeod } \\
\text { M. R. Veall }\end{array}$ & $\begin{array}{l}\text { The Dynamics of Food Deprivation and Overall } \\
\text { Health: Evidence from the Canadian National } \\
\text { Population Health Survey }\end{array}$ & 2 & $11 / 02$ \\
\hline 639 & G. Saint-Paul & Are Intellectual Property Rights Unfair? & 3 & $11 / 02$ \\
\hline 640 & $\begin{array}{l}\text { J. Hartog } \\
\text { N. Jonker } \\
\text { H. van Ophem }\end{array}$ & $\begin{array}{l}\text { Dual Track or Academic Route for Auditors: } \\
\text { Does It Matter? }\end{array}$ & 6 & $11 / 02$ \\
\hline 641 & $\begin{array}{l}\text { J. Hartog } \\
\text { L. Diaz Serrano }\end{array}$ & $\begin{array}{l}\text { Earning Risk and Demand for Higher Education: } \\
\text { A Cross-Section Test for Spain }\end{array}$ & 2 & $11 / 02$ \\
\hline 642 & $\begin{array}{l}\text { J. Hartog } \\
\text { A. Zorlu }\end{array}$ & $\begin{array}{l}\text { The Effect of Immigration on Wages in Three } \\
\text { European Countries }\end{array}$ & 1 & $11 / 02$ \\
\hline 643 & $\begin{array}{l}\text { A. Björklund } \\
\text { M. Sundström }\end{array}$ & $\begin{array}{l}\text { Parental Separation and Children's Educational } \\
\text { Attainment: A Siblings Approach }\end{array}$ & 6 & $11 / 02$ \\
\hline 644 & $\begin{array}{l}\text { J. D. Brown } \\
\text { J. S. Earle }\end{array}$ & $\begin{array}{l}\text { Job Reallocation and Productivity Growth Under } \\
\text { Alternative Economic Systems and Policies: } \\
\text { Evidence from the Soviet Transition }\end{array}$ & 4 & $11 / 02$ \\
\hline 645 & $\begin{array}{l}\text { M. Karanassou } \\
\text { H. Sala } \\
\text { D. J. Snower }\end{array}$ & $\begin{array}{l}\text { Long-Run Inflation-Unemployment Dynamics: } \\
\text { The Spanish Phillips Curve and Economic Policy }\end{array}$ & 3 & $11 / 02$ \\
\hline 646 & $\begin{array}{l}\text { L. Graham } \\
\text { D. Snower }\end{array}$ & The Return of the Long-Run Phillips Curve & 3 & $11 / 02$ \\
\hline 647 & $\begin{array}{l}\text { C. Grund } \\
\text { D. Sliwka }\end{array}$ & Envy and Compassion in Tournaments & 1 & $11 / 02$ \\
\hline 648 & $\begin{array}{l}\text { C. Schnabel } \\
\text { T. Schank } \\
\text { J. Wagner }\end{array}$ & $\begin{array}{l}\text { Works Councils - Sand or Grease in the } \\
\text { Operation of German Firms? }\end{array}$ & 3 & $11 / 02$ \\
\hline 649 & $\begin{array}{l}\text { J. van Ours } \\
\text { J. Veenman }\end{array}$ & $\begin{array}{l}\text { From Parent to Child: Early Labor Market } \\
\text { Experiences of Second-Generation Immigrants } \\
\text { in the Netherlands }\end{array}$ & 1 & $11 / 02$ \\
\hline 650 & $\begin{array}{l}\text { H. Battu } \\
\text { P. J. Sloane }\end{array}$ & Overeducation and Ethnic Minorities in Britain & 2 & $11 / 02$ \\
\hline 651 & E. Schlicht & $\begin{array}{l}\text { Social Evolution, Corporate Culture, and } \\
\text { Exploitation }\end{array}$ & 3 & $11 / 02$ \\
\hline 652 & E. Plug & $\begin{array}{l}\text { How Do Parents Raise the Educational } \\
\text { Attainment of Future Generations? }\end{array}$ & 5 & $11 / 02$ \\
\hline 653 & $\begin{array}{l}\text { W. Groot } \\
\text { E. Plug } \\
\text { H. Maassen van den } \\
\text { Brink }\end{array}$ & $\begin{array}{l}\text { Money for Health: The Compensating Variation } \\
\text { of Cardiovascular Diseases }\end{array}$ & 6 & $11 / 02$ \\
\hline
\end{tabular}

An updated list of IZA Discussion Papers is available on the center's homepage www.iza.org. 